\title{
Mediated facilitation in a four-stage chaining paradigm ${ }^{1,2}$
}

\section{JERAL R. WILLIAMS and IRWIN P. LEVIN, University of Iowa, Iowa City, Iowa}

Mediated facilitation was found in the $A-B, B-C, C-D, A-D$ chaining paradigm using methods that closely paralleled those of prior three-stage experiments that reliably produced inferred mediation effects. The $A$ terms were paralogs, the $B$ and $C$ terms were highly associated nouns, and the $D$ terms were CVCs. All four stages were executed in the laboratory. A mediated interference condition did not yield reliable interference effects.

Four-stage paradigms have had only limited success in producing inferred mediation effects (Horton \& Kjeldergaard, 1961; Jenkins, 1963; Kjeldergaard, 1968). Until recently the most consistent evidence for four-stage mediation was thought to be the studies utilizing one or more stages of assumed pre-experimental associations (McGehee \& Schulz, 1961; Russell \& Storms, 1955). However, an inferred mediation interpretation of the studies using one or more stages of assumed associations has been complicated by a study by Richardson (1968). Richardson has produced evidence that suggests that Russell and Storms' procedure for the selection of experimental words may have resulted in more direct associations being available to the mediated facilitation group than to the control group. Therefore, the facilitory effect found by anyone using Russell and Storms' materials may not have been entirely due to the implicit elicitation of mediational responses.

Recently, some studies (Grover, Horton, \& Cunningham, 1967; James \& Hakes, 1965) have offered evidence for four-stage mediation when all four stages were learned in the laboratory. However, in general the evidence for mediation effects using laboratory stages of learning is less reliable than the evidence from the experiments with assumed stages of association.

An examination of the studies that have required learning of all four stages in the laboratory reveals that little, if any, experimental work has been done with the four-stage forward chaining paradigm, A-B, B-C, C-D, A-D. The four-stage forward chaining paradigm would seem to have several advantages. First, a chaining paradigm is known to produce reliable inferred mediational effects in three-stage paradigms. Second; the mediational associations, A-B, B-C, and C-D, that would be assumed to occur on Stage 4 learning are all forward in direction. Third, the learning of the associations would be in the same temporal order as the associations would be assumed to occur during Stage 4 learning.

The present study thus attempted to parallel very closely the methods that have been shown to produce reliable inferred mediation effects in three-stage paradigms (Schulz \& Lovelace, 1964; Schulz \& Weaver, 1968) in order to determine if an inferred mediation effect (either facilitation or interference) could be reliably obtained in the four-stage forward chaining paradigm.

\section{DESIGN AND MATERIALS}

The three groups in the present experiment are represented as: Group F: A-B, B-C, C-D, A-D (facilitation); Group C: X-B, B-C, C-D, A-D (control); Group I: A-B, B-C, $C_{5}-D, A-D$ (interference). The $A$ and the $X$ terms were paralogs of low meaningfulness according to Taylor (1959). The B and C terms were "A" or "AA" nouns from the Thorndike-Lorge (1944) word count. Each $C$ word was the highest noun associated to one of the B words based on Palermo \& Jenkins (1964) norms. The D terms were CVCs within the 70-78 range on the Krueger (cf., Underwood \& Schulz, 1961, pp. 309-317) scale and within the 31-39 range on the Archer (1960) scale. In addition, the following restrictions were placed on the selected materials: (1) No paralog or CVC began with the same letter. (2) With only one exception (e.g., LATUK-TUP) no bigram combinations were repeated in either the paralogs or the CVCs. (3) No paralog had as its highest free-associate any of the subsequent nouns. (4) Internoun associations were kept minimal. (5) Formal similarity for CVCs was minimal.
An example of one item and its subsequent stages for Group $\mathrm{F}$ would be: Stage 1, RATAN-KING; Stage 2,KING-QUEEN; Stage 3, QUEEN-DIW; Stage 4, RATAN-DIW. For Group C a different paralog was inserted for RATAN on Stage 1 (e.g., HYRAX-KING), but the remaining stages were not changed. For Group 1 the Stage 3 items were re-paired in accord with the laboratory definition of mediated interference. That is, a CVC that subsequently appeared as a response item on Stage 4 , but with a different paralog than RATAN, was paired with QUEEN on Stage 3.

\section{PROCEDURE}

Four orders of each eight-item paired-associate (PA) list were typed on tape for presentation on a Stowe memory drum, model 459 B. Each S learned four successive PA lists (stages) by the anticipation method. For the first three stages each stimulus was exposed alone for $2 \mathrm{sec}$ and the stimulus and response pairs were exposed for $2 \mathrm{sec}$. The intertrial interval was $4 \mathrm{sec}$. The first three stages were performed to a criterion of three successive correct trials. The procedures for Stage 4 were the same as the prior stages, except each stimulus was exposed alone for $3 \mathrm{sec}$ and all Ss received 10 trials. The $S$ pronounced (or spelled) both the stimulus and the response items on all stages. Any $S$ that failed to reach criterion within 25 trials on Stage 1 was discarded. There were four Ss discarded for failure to reach criterion during Stage 1.

There were $16 \mathrm{Ss}$ assigned randomly to each group. The 48 experimental $S s$ and the four discarded $S s$ were students in introductory psychology at the University of Iowa and were participating to fulfill a course requirement.

\section{RESULTS}

The mean and standard deviation of the trials to criterion for each of the Groups F, C and I, for Stages 1, 2 and 3 are presented in Table 1 . The analysis of variance tests comparing groups at each of the first three stages revealed no significant differences, $F(2,45)=.08, .44,1.65$ for Stages 1,2 , and 3 respectively, $p>.10$ in each test.

The mean and standard deviation of the number of correct responses per trial for each of the Groups F, C, and I on Stage 4 is also shown in Table 1. Examination of the Stage 4 data shows that Group $F$ performed better than Group $C$, and that Group $C$ performed slightly better than Group I. The overall analysis of variance of number of correct responses on Stage 4 yielded a significant difference between groups, $F(2,45)=11.86, p<.01$. In order to test for inferred mediation effects, individual comparisons were made between Groups $F$ and $C$, and between Groups $C$ and $I$. The test of mediated facilitation (F vs $C$ ) was significant, $F(1,45)=12.60, p<.01$, and the test of mediated interference was not significant, $F(1,45)=1.25, p>.10$.

\section{DISCUSSION}

When Group F was compared to Group C on Stage 4 learning, strong evidence for the inference of mediated facilitation was found. That is, the superior performance of Group $F$ could be attributed to the implicit elicitation of a B-C mediational chain that provided a link between $A$ and $D$ terms that was not available to Group C.

Table 1

Mean Number of Trials to Criterion for All Conditions on Stages 1, 2, and 3; Mean Number of Correct Responses for 10 Trials on Stage 4

\begin{tabular}{|c|c|c|c|c|}
\hline & \multicolumn{3}{|c|}{ Trials to Criterion } & \multirow{2}{*}{$\frac{\text { Mean No. Correct }}{\text { Stage } 4}$} \\
\hline & Stage 1 & Stage 2 & Stage 3 & \\
\hline Group F & $\begin{array}{r}14.13 \\
(5.30)\end{array}$ & $\begin{array}{l}3.38 \\
(.72)\end{array}$ & $\begin{array}{l}13.88 \\
(5.92)\end{array}$ & $\begin{array}{c}63.44 \\
(12.50)\end{array}$ \\
\hline Group C & $\begin{array}{r}13.93 \\
(6.02)\end{array}$ & $\begin{array}{l}3.56 \\
(.89)\end{array}$ & $\begin{array}{l}16.94 \\
(7.05)\end{array}$ & $\begin{array}{c}48.19 \\
(11.74)\end{array}$ \\
\hline Group I & $\begin{array}{r}13.25 \\
(4.88)\end{array}$ & $\begin{array}{l}3.31 \\
(.71)\end{array}$ & $\begin{array}{c}17.94 \\
(6.82)\end{array}$ & $\begin{array}{c}43.38 \\
(12.24)\end{array}$ \\
\hline
\end{tabular}

Note. The standard deviations for each condition are given in the parentheses. 
Two factors of the design need comment. First, if you look at Stages 1 and 4 for the three groups, it is obvious that Groups $F$ and $I$ can be represented as A-B, A-D paradigms which are known to elicit negative transfer. However, Group $C$ can be represented as an X-B, A-D paradigm which would not be expected to yield negative transfer. If the control group (C) had been chosen as A-B, B-C. X-D, A-D then negative transfer would have been equated for all conditions thereby providing a more suitable control for the assessment of facilitation and interference effects. Notice however, the additional negative transfer in the X-D control group would have lowered Stage 4 performance for the control group and thus further enhanced mediated facilitation. Also, the lowering of Stage 4 performance for Group $C$ would have decreased whatever differences were present between Group $C$ and Group I. The latter effect suggests that in view of the small and unreliable interference effects that were found in the present study there would be a low probability of finding reliable mediated interference with the present methods, even with an X-D control.

Second, although the B-C stage is not an assumed stage it takes full advantage of the pre-experimental association strength that is available. It would be possible to represent the present paradigm as $A-B, B-B^{\prime}, B^{\prime}-D, A-D$. However, it seems preferable at the present time to represent Stage 2 learning as $B-C$ and then emphasize that Stage 2 materials are high in meaningfulness and high in associative strength.

Although the evidence strongly suggests inferred mediated facilitation effects, further research is necessary before any conclusion can be made as to whether the A-B, B-C, C-D, A-D paradigm is sensitive to mediation effects with a wide variation of manipulations or whether the inferred mediated facilitation in the present study is specific to the methods employed here.

\section{REFERENCES}

ARCHER, E. J. Re-evaluation of the meaningfulness of all possible CVC trigrams. Psychological Monographs, 1960, 74 (Whole No. 497).

GROVER, D. E., HORTON, D. L., \& CUNNINGHAM, M. Mediated facilitation and interference in a four-stage paradigm. Journal of Verbal Learning \& Verbal Behavior, 1967, 6, 42-46.
HORTON, D. L., \& KJELDERGAARD, P. M. An experimental analysis of associative factors in mediated generalization. Psychological Monographs, 1961, 75 (Whole No. 515).

JAMES, C. T., \& HAKES, D. T. Mediated transfer in a four-stage stimulus-equivalence paradigm. Journal of Verbal Learning \& Verbal Behavior, 1965, 4, 89-93.

JENKINS, J. J. Mediated associations: Paradigms and situations. In C. N. Cofer and B. S. Musgrave (Eds.), Verbal behavior and learning. New York: McGraw-Hill, 1963.

KJELDERGAARD, P. M. Transfer and mediation in verbal learning. In T. R. Dixon and D. L. Horton (Eds.), Verbal behavior and general behavior theory. New Jersey: Prentice-Hall, 1968.

McGEHEE, N. E., \& SCHULZ, R. W. Mediation in paired-associate learning. Journal of Experimental Psychology, 1961, 62, 565-570.

PALERMO, D. S., \& JENKINS, J. J. Word association norms, grade school through college. Minneapolis: University of Minnesota Press, 1964.

RICHARDSON, J. Implicit verbal chaining as the basis of transfer in paired-associate learning. Journal of Experimental Psychology, 1968, 76, 109-115.

RUSSELL, W., \& STORMS, L. Implicit verbal chaining in paired-associate learning. Journal of Experimental Psychology, 1955, 49, 287-293.

SCHULZ, R. W., \& LOVELACE, E. A. Mediation in verbal paired-associate learning: The role of temporal factors. Psychonomic Science, 1964, 1, 95-96.

SCHULZ, R., \& WEAVER, G. The A-B, B-C, A-C mediation paradigm: The effects of variations in A-C study and test interval lengths and strength of A-B or B-C. Journal of Experimental Psychology, 1968, 76, 303-311.

TAYLOR, J. D. The meaningfulness of three hundred and twenty words and paralogs. Unpublished doctoral dissertation, Duke University, 1959.

THORNDIKE, E. L., \& LORGE, I. The teachers word book of 30,000 words. New York: Columbia University, 1944.

UNDERWOOD, B. J., \& SCHULZ, R. W. Meaningfulness and verbal learning. Philadelphia: Lippincott, 1960.

\section{NOTES}

1. The authors wish to thank Dr. R. W. Schulz and Dr. G. Weaver for their helpful comments and criticism.

2. This research was supported in part by National Institute of Mental Health Grant MH 15741-01. 